CLINICAL STUDY

\title{
Role of insulin as a negative regulator of plasma endocannabinoid levels in obese and nonobese subjects
}

\author{
Vincenzo Di Marzo, An Verrijken ${ }^{1}$, Antti Hakkarainen ${ }^{2}$, Stefania Petrosino, Ilse Mertens ${ }^{1}$, Nina Lundbom ${ }^{2}$, \\ Fabiana Piscitelli, Jukka Westerbacka ${ }^{3}$, Aino Soro-Paavonen ${ }^{3}$, Isabel Matias, Luc Van Gaal ${ }^{1}$ \\ and Marja-Riitta Taskinen ${ }^{3}$ \\ Endocannabinoid Research Group, Institute of Biomolecular Chemistry, Consiglio Nazionale delle Ricerche, Via Campi Flegrei, 34, Comprensorio Olivetti, \\ 80078 Pozzuoli (NA), Italy, ${ }^{1}$ Department of Endocrinology, Diabetology and Metabolism, Antwerp University Hospital, UA, B-2650 Antwerp, \\ Belgium, ${ }^{2}$ Medical Imaging Center and ${ }^{3}$ Department of Medicine, Helsinki University Hospital, Biomedicum, Haartmaninkatu 8, PO Box 700 , \\ 00029 Helsinki, Finland \\ (Correspondence should be addressed to V Di Marzo; Email: vdimarzo@icmib.na.cnr.it)
}

\begin{abstract}
Objective: Endocannabinoids (ECs) control metabolism via cannabinoid receptors type $1\left(\mathrm{CB}_{1}\right)$. Their plasma levels are elevated in overweight type 2 diabetes (T2D) and in obese patients, and decrease postprandially in normoweight individuals. We investigated in two different cohorts of nonobese or obese volunteers whether oral glucose in glucose tolerance tests (OGTT) or acute insulin infusion during euglycemic hyperinsulinemic clamp affect plasma EC levels.

Design and methods: OGTT was performed in ten obese hyperinsulinemic patients (body mass index $(\mathrm{BMI})=35.8 \mathrm{~kg} / \mathrm{m}^{2}$, fasting insulin $\left.=14.83 \mathrm{mU} / \mathrm{l}\right)$, and ten normoweight normoinsulinemic volunteers $\left(\mathrm{BMI}=21.9 \mathrm{~kg} / \mathrm{m}^{2}\right.$, fasting insulin $\left.=7.2 \mathrm{mU} / \mathrm{l}\right)$. Insulin clamp was performed in 19 mostly nonobese men $\left(\mathrm{BMI}=25.8 \mathrm{~kg} / \mathrm{m}^{2}\right)$ with varying degrees of liver fat and plasma triglycerides (TGs), with $(n=7)$ or without T2D. Plasma levels of ECs (anandamide and 2-arachidonoylglycerol (2-AG)) were measured by liquid chromatography-mass spectrometry, before and 60 and 180 min after OGTT, and before and 240 and $480 \mathrm{~min}$ after insulin or saline infusion.

Results: Oral glucose load decreased anandamide plasma levels to an extent inversely correlated with BMI, waist circumference, subcutaneous fat, fasting insulin and total glucose, and insulin areas under the curve during the OGTT, and nonsignificantly in obese volunteers. Insulin infusion decreased anandamide levels to an extent that weakly, but significantly, correlated negatively with TGs, liver fat and fasting insulin, and positively with high density lipoprotein cholesterol. OGTT decreased 2-AG levels to a lower extent and in a way weakly inversely correlated with fasting insulin.

Conclusions: We suggest that insulin reduces EC levels in a way inversely related to anthropometric and metabolic predictors of insulin resistance and dyslipidemia.
\end{abstract}

European Journal of Endocrinology 161 715-722

\section{Introduction}

The endocannabinoid (EC) system and, in particular, the cannabinoid receptor type $1\left(\mathrm{CB}_{1}\right)$ and its endogenous agonists, the ECs anandamide and 2-arachidonoylglycerol (2-AG), are emerging as major players in the control of metabolism and, when malfunctioning, as one of the underlying causes of obesity, hyperglycemia, dyslipidemia, ectopic fat, insulin resistance, and type 2 diabetes (T2D) $(1,2)$. Animal studies have shown that antagonism of $\mathrm{EC}$ action at $\mathrm{CB}_{1}$ receptors counteracts body weight gain as well as the metabolic consequences of high fat diets in both mice and rats (3-5), whereas experimental EC overactivation causes $\mathrm{CB}_{1}$-mediated elevation of triglycerides (TGs) in lean mice (6). Clinical studies carried out in obese patients with the $\mathrm{CB}_{1}$ receptor antagonists, rimonabant and taranabant, have shown that these compounds cause significant weight loss and metabolic benefits in terms of reduction in insulin resistance and high TGs, and increase in high density lipoprotein (HDL) cholesterol $(7,8)$. Several human studies have found strong associations between high plasmatic EC levels and intraabdominal obesity, high TGs, low HDL cholesterol, and insulin resistance in obese $(9-11)$ as well as T2D patients (12). Since the concentrations of both anandamide and particularly 2-AG in the human plasma are, at best, tenfold lower than in most tissues, and in view of the fact that ECs are not circulating hormones but rather local mediators (1), it has been postulated that these measures reflect 'spill-over' of these compounds from peripheral tissues, rather than biologically active concentrations in blood cells. Accordingly, dysregulation of the EC levels is also observed in animal models of 
obesity, where it consists of an early and/or persistent elevation of anandamide and/or 2-AG levels in the liver, epidydimal fat, brown fat, pancreas, and skeletal muscle and of their reduction in the subcutaneous adipose tissue $(4,12-15)$. Such alterations have been proposed to result in $\mathrm{CB}_{1}$-mediated accumulation of fat in nonsubcutaneous depots and liver, reduction in adiponectin production, and insulin resistance in the liver and skeletal muscle, associated with reduced energy expenditure and enhanced insulin secretion from the pancreas (1).

Among the possible causes of the peripheral dysregulation of the EC system, the lack of negative control by insulin on EC levels has been suggested by previous studies $(12,16,17)$. In particular, experiments in isolated cells have shown that conditions mimicking high glucose and/or insulin resistance can enhance EC levels in models of adipocytes and pancreatic $\beta$-cells $(12,17)$. In contrast, anandamide levels are reduced following incubation of 'normoglycemic' $\beta$-cells with insulin, or in the postprandial plasma of normoglycemic normoweight patients (12). Accordingly, the expression of the anandamide-degrading enzyme, fatty acid amide hydrolase (FAAH), is elevated in insulintreated subcutaneous adipocytes from normoglycemic nonobese subjects (16). However, no direct evidence exists for a cause-effect relationship between insulin action and decreased EC levels in vivo in humans, and it is not known how metabolic factors such as obesity and hyperglycemia might influence this relationship.

In the present study, we investigated in two different cohorts of nonobese and obese volunteers whether the insulin response to oral glucose load in oral glucose tolerance tests (OGTT) or to acute insulin infusion during euglycemic hyperinsulinemic clamp (EHC) affects plasma EC levels, which have been used here and previously $(9-11,18,19)$ as an indirect measure of peripheral EC system activity. Furthermore, we have studied the potential impact of various anthropometric and metabolic parameters on the putative changes in EC levels induced by these interventions.

\section{Materials, subjects, and methods}

\section{Subjects}

Two different cohorts of volunteers were used for the two studies carried out here. In the first study, in which the effect of an oral glucose load on EC levels was investigated, ten normoweight and ten obese volunteers, under no medication that could affect glucose or insulin levels, were employed (Table 1). In the second study, in which the effect of insulin infusion on EC levels was investigated, 19 volunteers within a wide range of body mass index (BMI) participated (Table 2). Seven of these patients had T2D, two of whom were treated with diet alone, two with diet and sulfonylurea, and three
Table 1 Metabolic and anthropometric parameters of the normoweight and obese volunteers participating in the oral glucose tolerance test (OGTT) experiments. Values were compared by using the Mann-Whitney test.

\begin{tabular}{|c|c|c|c|}
\hline & $\begin{array}{l}\text { Normoweight } \\
\quad(n=10)\end{array}$ & $\begin{array}{l}\text { Obese } \\
(n=10)\end{array}$ & $\begin{array}{c}\text { Statistical } \\
\text { significance }\end{array}$ \\
\hline Gender & $6 \mathrm{~F} / 4 \mathrm{M}$ & $6 \mathrm{~F} / 4 \mathrm{M}$ & \\
\hline Age (years) & $44 \pm 2$ & $44 \pm 2$ & $P>0.1$ \\
\hline Weight $(\mathrm{kg})$ & $68.1 \pm 4.0$ & $108.4 \pm 4.7$ & $P=0.0002$ \\
\hline BMI $\left(\mathrm{kg} / \mathrm{m}^{2}\right)$ & $21.9 \pm 0.6$ & $35.8 \pm 1.1$ & $P=0.00016$ \\
\hline Waist (cm) & $78.0 \pm 2.2$ & $114.0 \pm 2.6$ & $P=0.00016$ \\
\hline $\begin{array}{l}\text { L4-L5 visceral } \\
\text { fat }\left(\mathrm{cm}^{2}\right)\end{array}$ & $63.8 \pm 8.7$ & $187.2 \pm 15.6$ & $P=0.00021$ \\
\hline $\begin{array}{l}\text { L4-L5 subcuta- } \\
\text { neous fat }\left(\mathrm{cm}^{2}\right)\end{array}$ & $180.6 \pm 24.8$ & $537.0 \pm 47.5$ & $P=0.00021$ \\
\hline $\begin{array}{l}\text { Fasting glucose } \\
(\mathrm{mmol} / \mathrm{l})\end{array}$ & $4.58 \pm 0.12$ & $4.97 \pm 0.16$ & $P=0.0887$ \\
\hline $\begin{array}{l}\text { Fasting insulin } \\
(\mathrm{mU} / \mathrm{l})\end{array}$ & $7.2 \pm 1.0$ & $14.8 \pm 1.7$ & $P=0.00051$ \\
\hline $\begin{array}{l}\text { Triacylglycerols } \\
(\mathrm{mmol} / \mathrm{l})\end{array}$ & $0.89 \pm 0.054$ & $2.45 \pm 0.33$ & $P=0.00045$ \\
\hline AÙC glucose & $18971 \pm 960$ & $21785 \pm 921$ & $P=0.049$ \\
\hline AUC insulin & $4839 \pm 446$ & $13334 \pm 2385$ & $P=0.0032$ \\
\hline
\end{tabular}

with a combination therapy of sulfonylurea, metformin, and diet. The other subjects were taking no medication that could affect glucose or insulin levels. All subjects gave informed consent to the study and received appropriate treatments. The study design was approved by the ethics committees of Helsinki University Central Hospital and of the Antwerp University Hospital, and each participant gave written informed consent. All samples were collected in accordance with the Declaration of Helsinki.

\section{Methods for the assessment of anthropometric and metabolic parameters}

All anthropometric measurements were performed in the morning, with patients in fasting conditions and undressed. BMI was calculated as weight in kilograms over height $^{2}$ in square meters. Waist circumference was measured at the mid-level between the lower rib margin and the iliac crest. Body composition was determined by bioimpedance analysis as described by Lukaski et al. (20), and fat mass percentage was calculated using the formula of Deurenberg et al. (21). In the normoweight and obese volunteers participating in the first study, a computer tomography-scan at L4-L5 level was performed to measure the cross-sectional area of total abdominal adipose tissue area, visceral abdominal adipose tissue (VAT), and subcutaneous abdominal adipose tissue (SAT) according to previously described methods (22). First, the total area of abdominal adipose tissue was measured at -190 to -30 Hounsfield units. Subsequently, the area of VAT was distinguished from SAT by manually tracing the abdominal muscular wall separating the two adipose tissue compartments. In these patients, a fasting blood sample was taken 
Table 2 Metabolic and anthropometric parameters of the normoweight/overweight borderline male volunteers participating in the euglycemic hyperinsulinemic clamp (EHC) experiments. Values were compared by using the Mann-Whitney test.

\begin{tabular}{|c|c|c|c|}
\hline & $\begin{array}{c}\text { Nondiabetic } \\
(n=12)\end{array}$ & $\begin{array}{c}\text { With type } 2 \\
\text { diabetes } \\
(n=7)\end{array}$ & $\begin{array}{c}\text { Statistical } \\
\text { significance }\end{array}$ \\
\hline Gender & $12 \mathrm{M}$ & $7 \mathrm{M}$ & \\
\hline Age (years) & $49.5 \pm 3.0$ & $56.3 \pm 3.8$ & $P>0.1$ \\
\hline Weight (kg) & $82.2 \pm 2.6$ & $90.9 \pm 3.3$ & $P=0.047$ \\
\hline BMI $\left(\mathrm{kg} / \mathrm{m}^{2}\right)$ & $26.3 \pm 0.8$ & $28.5 \pm 1.6$ & $P>0.1$ \\
\hline Waist $(\mathrm{cm})$ & $95.4 \pm 2.5$ & $101.4 \pm 2.5$ & $P>0.1$ \\
\hline $\begin{array}{l}\text { L4-L5 visceral fat } \\
\quad\left(\mathrm{cm}^{2}\right)\end{array}$ & $121.2 \pm 14.3$ & $148.7 \pm 24.2$ & $P=0.022$ \\
\hline $\begin{array}{l}\text { L4-L5 subcutane- } \\
\text { ous fat }\left(\mathrm{cm}^{2}\right)\end{array}$ & $164.5 \pm 13.4$ & $179.0 \pm 17.8$ & $P>0.1$ \\
\hline Liver fat (\%) & $2.8 \pm 0.7$ & $11.7 \pm 2.5$ & $P=0.00295$ \\
\hline ALAT (unit/l) & $27.5 \pm 2.0$ & $37.1 \pm 6.1$ & $P>0.1$ \\
\hline $\begin{array}{l}\text { Fasting glucose } \\
(\mathrm{mmol} / \mathrm{l})\end{array}$ & $5.7 \pm 0.2$ & $9.3 \pm 1.2$ & $P=0.0006$ \\
\hline $\begin{array}{l}\text { Fasting insulin } \\
(\mathrm{mU} / \mathrm{l})\end{array}$ & $5.5 \pm 1.0$ & $12.9 \pm 2.5$ & $P=0.006$ \\
\hline $\begin{array}{l}\text { Triacylglycerols } \\
(\mathrm{mmol} / \mathrm{l})\end{array}$ & $1.32 \pm 0.12$ & $2.57 \pm 0.30$ & $P=0.003$ \\
\hline $\begin{array}{l}M \text { value }(\mu \mathrm{mol} / \mathrm{kg} \\
\text { per min) }\end{array}$ & $7.22 \pm 0.53$ & $4.49 \pm 1.14$ & $P=0.028$ \\
\hline ApoB (mg/dl) & $106.3 \pm 6.7$ & $125.6 \pm 4.2$ & $P=0.063$ \\
\hline $\begin{array}{l}\text { HDL cholesterol } \\
(\mathrm{mmol} / \mathrm{l})\end{array}$ & $1.38 \pm 0.49$ & $1.01 \pm 0.53$ & $P=0.0013$ \\
\hline $\begin{array}{l}\text { Adiponectin } \\
\text { (ng/ml) }\end{array}$ & $\begin{array}{r}9606.8 \pm \\
1059.5\end{array}$ & $\begin{array}{r}6831.4 \pm \\
1038.3\end{array}$ & $P>0.1$ \\
\hline
\end{tabular}

from an antecubital vein to determine the fasting levels of TGs, glucose, and insulin. An OGTT was performed with $75 \mathrm{~g}$ of glucose, with blood samples taken to determine glucose in the fasted state and 15, 30, 60, 90, 120,150 , and $180 \mathrm{~min}$ after the glucose load. During the OGTT, insulin was also determined 30, 60, 120, and $180 \mathrm{~min}$ after the glucose load. Plasma glucose and TGs were measured on Vitros 750 XRC (Ortho Clinical Diagnostics, Johnson \& Johnson, High Wycombe Bucks, UK). Insulin levels were measured with the Medgenic two-site IRMA assay (BioSource, Nivelles, Belgium). The total glucose and insulin areas under the curve (AUC) during the OGTT were determined with the trapezoid method (23).

In the cohort of volunteers employed in the second study, subcutaneous and intra-abdominal fat volumes and liver fat content were measured using magnetic resonance imaging and magnetic spectroscopy as previously described (24). The mean of $16 \mathrm{~T}$-weighted transaxial scans at L4-L5 level was used to calculate the intra-abdominal and subcutaneous fat areas $\left(\mathrm{cm}^{2}\right)$. The biochemical analyses of plasma TGs, ApoB, HDL cholesterol, insulin, and glucose were carried out as previously described (25), and alanine aminotransferase (ALAT) was determined according to European committee for Clinical Laboratory Standards. Fasting plasma adiponectin levels were determined with the human adiponectin ELISA kit (B-Bridge International, San Jose, CA, USA).
Differences in the anthropometric and metabolic parameters between nonobese and obese subjects in the first study, and between nondiabetic and T2D subjects in the second study, were evaluated by means of the Mann-Whitney $U$ test.

EHC studies The patients were admitted at $0730 \mathrm{~h}$ after an overnight fast. An indwelling cannula was inserted into an antecubital vein for infusions, and a second cannula was inserted retrogradely into a heated hand vein to obtain arterialized venous blood for sampling. At $0 \mathrm{~min}$, a primed-continuous infusion of insulin (Human Actrapid; Novo Nordisk, Copenhagen, Denmark) was started at a rate of continuous infusion of $1 \mathrm{mU} / \mathrm{min}$ per $\mathrm{kg}$. Plasma glucose was maintained at its fasting level by a variable rate infusion of glucose $(200 \mathrm{~g} / \mathrm{l})(26)$. The infusion rate was determined empirically based on plasma glucose measurements that were performed every 5-10 min from arterialized venous blood. Whole body insulin sensitivity ( $M$ value) was calculated from the mean values of the second hour of glucose infusion rate after correcting for changes in the glucose pool size (26) and was expressed as $\mu \mathrm{mol} / \mathrm{min}$ per $\mathrm{kg}$ body weight. Insulin infusion continued for $8.5 \mathrm{~h}$, and the participants remained fasting until $1700 \mathrm{~h}$ when they were served a hospital meal. During the control study, saline was infused at a rate of $200 \mathrm{ml} / \mathrm{h}$, which is approximately equal to volume of insulin and glucose infusions during the clamp. The blood samples for measurements of plasma EC levels were taken $30 \mathrm{~min}$ before insulin/saline infusions and at 240 and $480 \mathrm{~min}$ following the initiation of insulin/saline infusions.

\section{Measurement of plasmatic EC levels}

Blood samples were taken on heparin, immediately centrifuged free of erythrocytes at $4{ }^{\circ} \mathrm{C}$, and then kept frozen at $-80{ }^{\circ} \mathrm{C}$ until analysis. Under these conditions, ECs are stable towards oxidation for up to 6 months. Within 6 months of blood sampling, EC levels were measured by isotope dilution liquid chromatographyatmospheric pressure chemical ionization-mass spectrometry (LC-APCI-MS) as previously described (10). In particular, before thawing, $\mathrm{d}_{5}-2-\mathrm{AG}(5 \mathrm{pmol})$ and $\mathrm{d}_{8}$-anandamide $(5 \mathrm{pmol})$, obtained from Cayman Chemicals (Ann Arbor, MI, USA), were added to each sample, and lipids were then extracted and prepurified as described (10). The isomerization of 2-AG to its 1- and 3-isomers occurring during the extraction, purification, and LC-MS analysis (27) was taken into account since also the internal deuterated 2-AG underwent similar isomerization, and the chromatographic procedure used (C18 Phenomenex column, 15 $\times 1.5 \mathrm{~cm}, 3 \mu \mathrm{m}$ particle size, eluted isocratically with methanol/water/acetic acid 85:15:0.1 by vol.) allows for the separation of 2-AG (11 min) from 1(3)-AG (12.5 $\mathrm{min})$. Therefore, the peaks corresponding to all isomers were added up and quantified by isotope dilution with those of the internal deuterated standard. 
Data are reported as means \pm s.E.M. Differences in the amounts of ECs following OGTT in nonobese and obese subjects were analyzed by repeated-measures ANOVA. For the insulin clamp study, saline and clamp curves were compared, with correction of the baseline values (before the clamp) using repeated-measures ANCOVA. Differences in the amounts of ECs between two groups of volunteers (i.e. between obese and normoweight, and between normoglycemic and T2D volunteers) were analyzed by the Student-Newman-Keuls's test. Correlations between changes $(\Delta)$ in EC levels, normalized to basal levels $\left(\Delta / T_{0}, \Delta=T_{0}-T\right)$ in the OGTT experiments, or to the corresponding saline infusion levels $\left(\Delta / T_{\text {saline, }}\right.$, $\left.\Delta=T_{\text {saline }}-T\right)$ in the EHC experiments, and other variables at baseline were assessed by Pearson's correlations. In the EHC experiments, the EC levels measured after saline infusions at the corresponding times were used as controls since plasma EC levels are known to change during the day and following intervals of time longer than $3 \mathrm{~h}$ (V Di Marzo \& S Petrosino, unpublished observations). Normalization of $\Delta$ values to baseline levels was necessary in the OGTT experiments because in this case the basal plasma levels of anandamide $\left(T_{0}\right)$ were significantly higher in obese than in normoweight volunteers. A $P$ value $<0.05$ indicated statistical significance.

\section{Results and discussion}

\section{Effect of glucose on EC levels in normoweight and obese volunteers}

In normoweight/normoinsulinemic volunteers (Table 1), the oral glucose load caused a statistically significant overall reduction in anandamide levels $(P=0.013$, by repeated-measures ANOVA), a reduction at $60 \mathrm{~min}(P=0.046)$, and a further reduction at $180 \mathrm{~min}(P=0.008$; Fig. 1A). Oral glucose load caused a statistically significant overall reduction in 2-AG levels $(P=0.028)$, and a reduction at $180 \mathrm{~min}(P=0.017)$, but not at $60 \mathrm{~min}(P=0.338$; Fig. 1A). In obese hyperinsulinemic volunteers (Table 1), whose AUC for glucose and insulin was significantly higher than those of normoweight volunteers (Table 1), baseline fasting anandamide, but not $2-\mathrm{AG}$, levels were significantly higher than in normoweight/normoinsulinemic volunteers, and did not change significantly following oral glucose either at 60 or $180 \mathrm{~min}$ (Fig. 1B). Also, the decrease in 2-AG levels at $180 \mathrm{~min}$ in this case did not reach statistical significance (Fig. 1B). When pooling together both normoweight and obese volunteers, the baseline fasting levels of anandamide correlated positively with BMI $\left(r^{2}=0.68 ; P<0.0001\right)$, waist circumference $\left(r^{2}=0.66 ; P<0.0001\right)$, VAT $\left(r^{2}=0.65\right.$; $P<0.0001)$, SAT $\left(r^{2}=0.50 ; P=0.0005\right)$, and TG levels $\left(r^{2}=0.44 ; P=0.0018\right)$. By contrast, 2-AG levels correlated positively only with TG levels $\left(r^{2}=0.46\right.$;
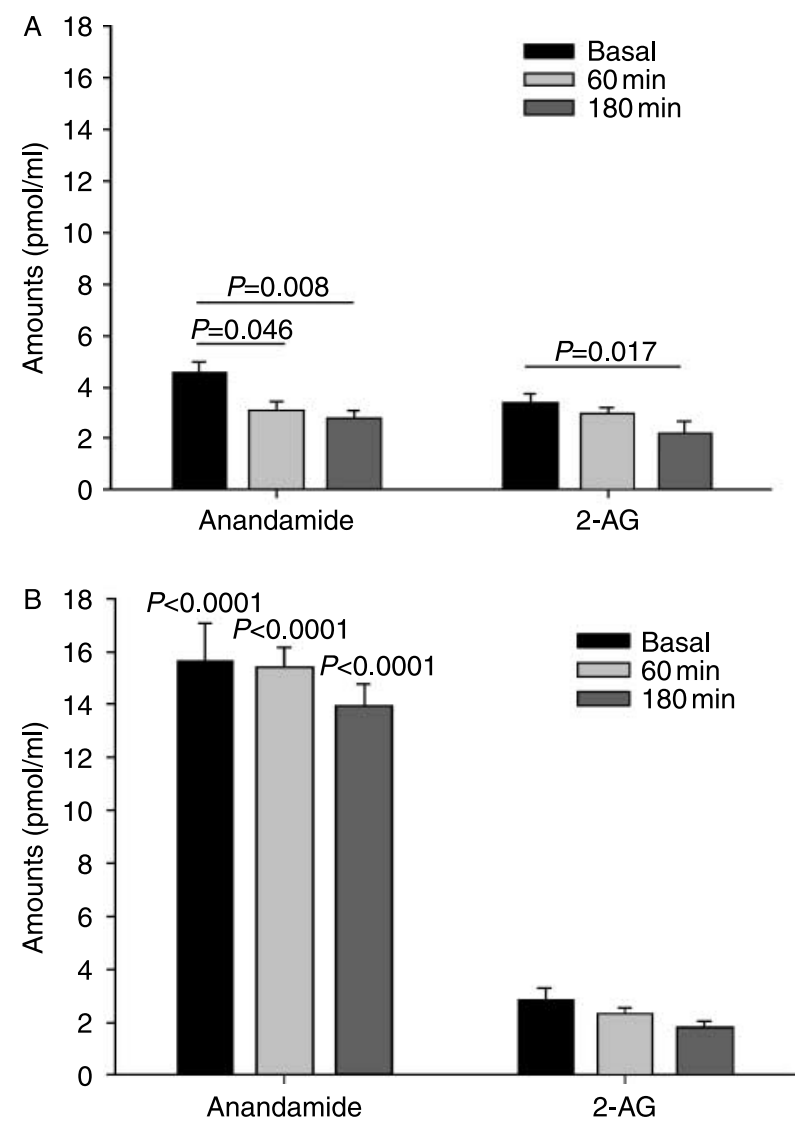

Figure 1 Effect of OGTT on anandamide and 2-arachidonoylglycerol (2-AG) plasma levels in normoweight/normoinsulinemic volunteers $(A)$ and obese/hyperinsulinemic volunteers $(B)$ (Table 1 for volunteers data). Data are expressed as means \pm S.E.M. of $n=10$ in each group and were compared by means of repeated-measures ANOVA. In (B) data for anandamide were compared with the corresponding values in (A) by the Student-Newman-Keuls's test ( $P$ values shown on each bar).

$P=0.03)$, and only in obese individuals. The normalized $(\Delta$ /baseline) oral glucose-induced changes of anandamide levels at 60 and $180 \mathrm{~min}$ correlated negatively with BMI $\left(r^{2}=-0.23 ; P=0.031\right.$ and $r^{2}=$ $-0.38 ; P=0.0037$ respectively), waist circumference $\left(r^{2}=-0.28 ; P=0.016\right.$ and $r^{2}=-0.44 ; P=0.0014$ respectively), and SAT $\left(r^{2}=-0.28 ; P=0.015\right.$ and $r^{2}=-0.33 ; P=0.0077$ respectively), and, at $180 \mathrm{~min}$ only, with fasting insulin levels $\left(r^{2}=-0.38\right.$; $P<0.0035)$ and fasting glucose levels $\left(r^{2}=-0.21\right.$; $P<0.041)$. Importantly, the $\Delta$ /baseline values for anandamide at both 60 and $180 \mathrm{~min}$ correlated negatively with both AUC's for glucose $\left(r^{2}=-0.31\right.$; $P=0.01$ and $r^{2}=-0.21 ; P=0.04$ respectively) and, particularly, AUC's for insulin $\left(r^{2}=-0.36 ; P=0.005\right.$ and $r^{2}=-0.46 ; P=0.001$ respectively). No such correlations were found for the normalized OGTTinduced changes of 2-AG levels, except for a trend with fasting insulin at $180 \mathrm{~min}\left(r^{2}=-0.18\right.$; $P=0.061)$. 


\section{Effect of acute insulin infusion on EC levels in male volunteers}

The cohort employed for this second part of the study (Table 2) was composed of 19 male volunteers with a normoweight/overweight borderline BMI, with or without T2D and, in some cases, with elevated fasting insulin levels and liver fat and reduced HDL cholesterol levels. However, no statistically significant difference was observed between the anandamide or 2-AG basal plasma levels of nondiabetic and T2D volunteers at baseline (Fig. 2A), nor at 240 and 480 min postsaline infusion (data not shown). The basal levels of 2-AG correlated positively with TG levels $\left(r^{2}=0.21 ; P<0.05\right)$ and ApoB levels $\left(r^{2}=0.21 ; P=0.05\right)$. No correlation was found between the basal levels of anandamide and any of the anthropometric or biochemical parameters measured.

The insulin infusion caused a decrease in anandamide, but not 2-AG, plasma levels (Fig. 2B). With repeated-measures ANCOVA, using baseline values as a covariate, we found for anandamide a $P$ value $<0.0001$ for TIME $\times$ INSULIN, whereas, for $2-A G$, the $P$ value was 0.367. A significant difference was also observed between the insulin infusion-induced $\Delta$ 's of EC levels of nondiabetic and T2D volunteers at 240 min postinfusion, with a significantly smaller decrease being observed for anandamide (mean $\Delta$ from $1.94 \pm 0.30$ to $1.07 \pm 0.43 \mathrm{pmol} / \mathrm{ml}, \quad P=0.027)$, and a negative decrease for 2 -AG (mean $\Delta$ from $1.03 \pm 1.50$ to $-4.60 \pm 3.02 \mathrm{pmol} / \mathrm{ml}, \quad P=0.019)$, in $\mathrm{T} 2 \mathrm{D}$ patients (Fig. 2C).

In this second study, only weak correlations were found between insulin infusion-induced $\Delta$ 's of blood EC levels and parameters of insulin resistance, hepatic fat and inflammation, dyslipidemia, and dyslipoproteinemia. Thus, for example, insulin infusion-induced decreases in anandamide levels correlated negatively with fasting insulin at $240 \mathrm{~min}\left(r^{2}=-0.21\right.$; $P=0.044)$; with TG levels at both 240 and $480 \mathrm{~min}$ $\left(r^{2}=-0.21 ; P=0.047\right.$ and $r^{2}=-0.23 ; P=0.039$ respectively); with ALAT at $240 \mathrm{~min}\left(r^{2}=-0.27\right.$; $P=0.024)$; and with ApoB levels at $480 \mathrm{~min}\left(r^{2}=\right.$ $-0.26 ; P=0.024)$; but positively with HDL cholesterol levels at both 240 and $480 \mathrm{~min}\left(r^{2}=0.27 ; P=0.021\right.$ and $r^{2}=0.27 ; P=0.024$ respectively). The insulin infusion-induced $\Delta$ 's of 2-AG levels correlated only with fasting insulin at $240 \mathrm{~min}\left(r^{2}=-0.25\right.$; $P=0.030)$. No stronger correlations were found when using instead normalized insulin infusion-induced changes $(\Delta /$ saline $)$ of EC levels. In the case of anandamide, these correlated negatively with TG levels at both 240 and $480 \mathrm{~min}\left(r^{2}=-0.24 ; P=0.031\right.$ and $r^{2}=-0.28 ; P=0.02$ respectively); with fasting insulin, liver fat, and ALAT at $240 \mathrm{~min}\left(r^{2}=-0.22 ; P=0.043\right.$, $r^{2}=-0.23 ; P=0.038 ;$ and $r^{2}=-0.25 ; P=0.028$ respectively); and with intra-abdominal fat at $480 \mathrm{~min}$ $\left(r^{2}=-0.24 ; P=0.04\right)$; but positively with HDL
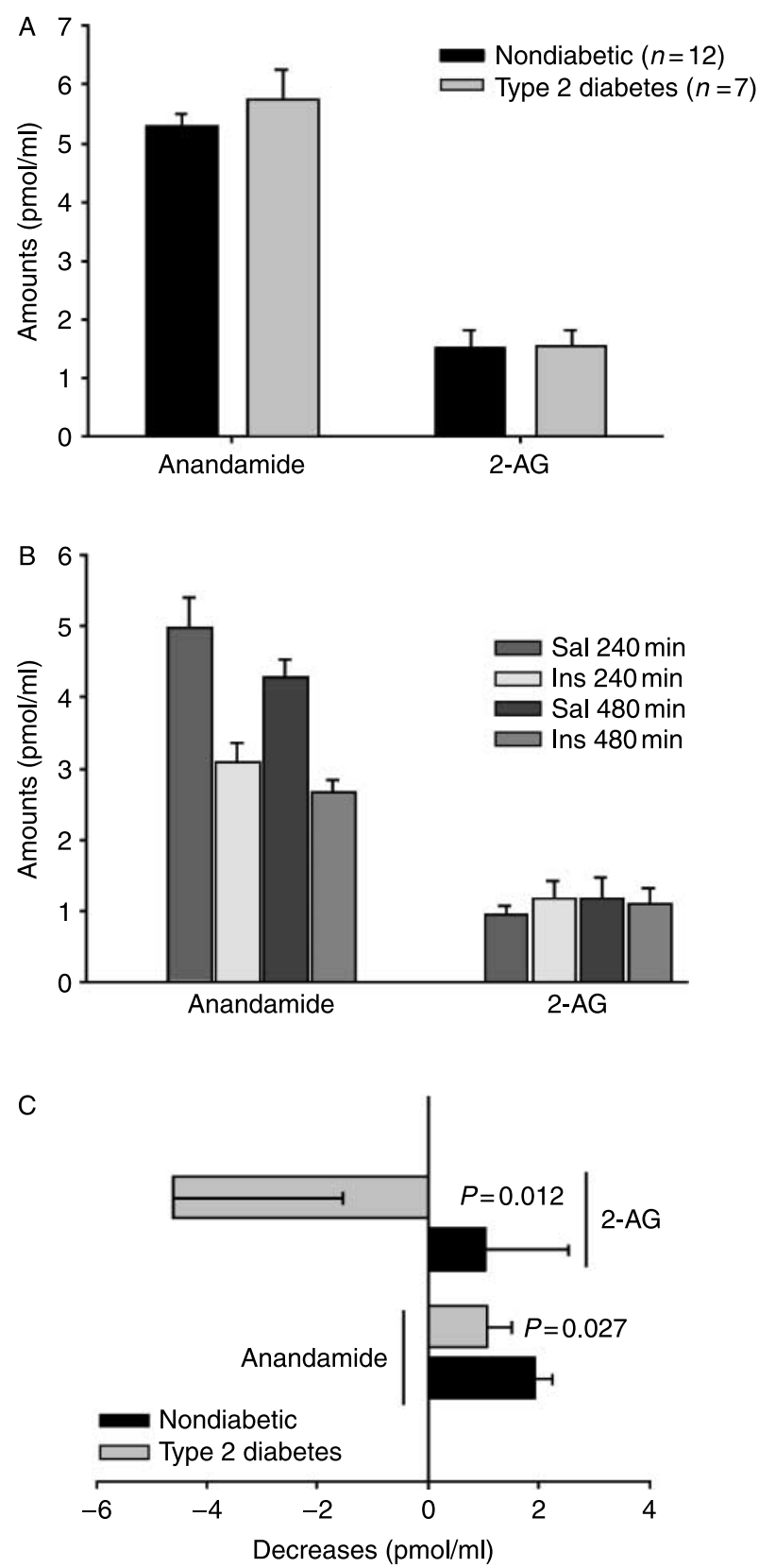

Figure 2 Basal fasting anandamide and 2-arachidonoylglycerol (2-AG) plasma levels in normoweight/overweight borderline male volunteers with $(n=7)$ and without $(n=12)$ type 2 diabetes $(\mathrm{A})$, their changes (B) in the whole cohort $(n=19)$ at 240 and $480 \mathrm{~min}$ following saline infusion (Sal) or insulin infusion clamp (Ins), and (C) their decreases at 240 min following saline insulin versus saline infusion in either nondiabetic or type 2 diabetics, taken separately. In (A), blood samples were taken $\mathbf{3 0}$ min prior to insulin or saline infusion. Data are expressed as means \pm s.E.M. and were compared between diabetic and nondiabetic by the Student-Newman-Keuls's test in (A). In (B), saline and clamp curves were compared, with correction of the baseline values (before the clamp) using repeatedmeasures ANCOVA and, for AEA, ${ }^{a} P<0.0001$ for TIME $\times$ INSULIN was found, whereas, for 2-AG, the difference was not significant $(P=0.367)$. In $(C)$ changes were compared by the StudentNewman-Keuls's test. 
cholesterol levels at both 240 and $480 \mathrm{~min}\left(r^{2}=0.28\right.$; $P=0.02$ and $r^{2}=0.30 ; P=0.016$ respectively). On the other hand, the normalized insulin infusion-induced changes of 2-AG levels did not correlate with any of the anthropometric or biochemical parameters measured.

\section{Discussion}

Previous data suggest that both glucose and insulin may affect EC biosynthesis and degradation in isolated cells $(12,16,17)$. Therefore, in this study, we aimed at gaining direct evidence, in intervention studies carried out in two different cohorts of volunteers, of potential effects of either oral glucose load or insulin infusion on plasma EC levels. We first wanted to understand whether, during oral glucose load, the subsequent elevation of glucose and insulin plasma levels is accompanied by changes in plasma EC levels in normoweight and normoinsulimic men and women. Despite the fact that, in isolated cells, glucose can cause elevation of EC levels $(12,17)$, we found here a strong decrease in EC levels at both 60 and, particularly, $180 \mathrm{~min}$ of the OGTT. The decreased blood EC levels observed following OGTT might suggest that insulin exerts a negative effect on plasma EC levels, as previously suggested in studies with isolated adipocytes and $\beta$-cells $(12,17)$. In agreement with this hypothesis, we observed that the levels of either anandamide or 2-AG did not decrease significantly during the OGTT in obese hyperinsulinemic volunteers who were insulin resistant. This finding is in agreement with the lack of stimulatory effect of insulin on FAAH expression in adipocytes from obese individuals (16), since lack of FAAH upregulation should cause lack of anandamide downregulation.

To further investigate the nature of the oral glucose load-induced decreases in EC levels, we evaluated the correlations of these changes with various anthropometric and metabolic parameters that had been measured in the two study groups. In agreement with the possible role of insulin sensitivity as a determinant for decreases in EC levels, we found that the decreases in anandamide observed at $180 \mathrm{~min}$ were negatively correlated with fasting insulin and glucose levels. More importantly, the OGTT-induced decreases in anandamide levels always strongly and negatively correlated with the AUC values for insulin, which are a very strong predictor of insulin resistance. The decreases in anandamide levels at both 60 and $180 \mathrm{~min}$ during the OGTT correlated negatively also with waist circumference, BMI, and SAT.

VAT, but not SAT, was previously shown to strongly correlate with plasma 2-AG, but not anandamide, levels in cross-sectional and intervention studies carried out in obese men with a much higher (at least twofold) average VAT/SAT ratio than that observed even in the obese volunteers employed in the present study
$(10,11)$. The significantly lower degree of VAT in the present cohort, which also included women, might also explain why, in contrast to the previous observations in abdominally obese men (9-11), the present subjects exhibited higher baseline levels of anandamide, but not of 2-AG, than normoweight volunteers, and why only baseline anandamide levels in both groups correlated positively with BMI, waist circumference, VAT, and SAT. In our volunteers, however, we did confirm the strong direct correlation between 2-AG, but not anandamide, baseline levels, and TG levels (9-11). It must be pointed out that anandamide and 2-AG tissue and plasma levels have been found very often to change in different ways in several physiological and pathological conditions, and in both laboratory animals and humans. This probably reflects the fact that the two compounds might play different roles, as anandamide, for example, is known to interact also with noncannabinoid receptors (28).

Since the results in this cohort study suggested a possible role of insulin in controlling peripheral EC levels, we aimed at gaining direct evidence of this by studying the effect of insulin infusion on EC levels utilizing the euglycemic clamp. Given the significant correlations between BMI and OGTT-induced decreases in anandamide levels observed in the first cohort, we chose to perform the insulin clamps in a cohort of volunteers with a wide range of BMI (from 22.2 to $35.3 \mathrm{~kg} / \mathrm{m}^{2}$, with mean $\mathrm{BMI}=25.8 \mathrm{~kg} / \mathrm{m}^{2}$ ). This strategy aimed at reducing the potential impact of BMI, which is not a strong correlate of insulin resistance, but is still associated with high plasma EC levels $(9,19)$. In this cohort of 19 individuals, strong differences existed in terms of dyslipidemia, liver fat, HDL cholesterol and of the presence of T2D, which we thought would allow us to speculate about the possible role of these factors as predictors of plasma EC levels and their changes following EHC.

In agreement with the results of the first study, we found that plasma anandamide levels were decreased during insulin infusion as compared with saline infusion, at both 240 and $480 \mathrm{~min}$ postinfusion. We also found that significantly smaller insulin-induced decreases in anandamide levels at 240 min postinfusion were observed in T2D patients, whereas 2-AG levels even tended to increase. This finding was not surprising in view of the fact that $\mathrm{T} 2 \mathrm{D}$ patients have little residual insulin sensitivity. These data strongly suggest that insulin can be a negative regulator of blood 2-AG and, particularly, anandamide levels in only insulinsensitive subjects.

Interestingly, the presence of $\mathrm{T} 2 \mathrm{D}$ per se (and the subsequent hyperglycemia), unlike what has previously been observed in overweight/obese (BMI 33) T2D patients of older age (65.7) and mixed gender, but with comparable elevation of triglyceridemia $(2.0 \mathrm{nmol} / \mathrm{l})$, fasting glucose, and total cholesterol (12), was not associated with elevated fasting EC levels, suggesting 
that the copresence of $\mathrm{BMI}>28$ and/or older age is necessary to observe a stronger basal EC tone in T2D (12). However, since T2D patients are clearly also insulin resistant, it is reasonable to suggest, based on the present data, that they are likely to always exhibit higher postprandial anandamide levels.

When we attempted to correlate, in the whole cohort, some important predictors of insulin resistance and/or dyslipidemia, i.e. high fasting insulin, TGs, liver fat and ApoB, and low HDL cholesterol, with the capacity of insulin to lower EC plasma levels at 240 and/or $480 \mathrm{~min}$ postinfusion, we found negative as well as weak correlations for anandamide, whereas insulin infusion-induced changes in 2-AG levels correlated negatively only with fasting insulin, and only at $240 \mathrm{~min}$ postinfusion. This suggests that, even in nonobese men, a postprandial overactivity of the peripheral EC system might be determined, perhaps not by insulin resistance, fatty liver, and dyslipidemia individually, but at least by their concomitant presence.

We also found that, even in this cohort of men with moderate intra-abdominal adiposity, fasting 2-AG levels correlate with TG (and ApoB) levels, as shown above and previously in obese patients (9-11), whereas no such correlation is seen with fasting anandamide levels. Thus, in these men, while TG and ApoB appear to be associated with high 2-AG levels independently of the effects of insulin, these same metabolic factors as well as high liver fat and fasting plasma insulin, and low HDL cholesterol, are weakly associated only with impaired insulin-induced decreases of anandamide levels.

In conclusion, we provided here novel evidence suggesting that insulin negatively controls plasma EC, and particularly anandamide, levels, which, in turn, might reflect EC spillover from peripheral organs. This control seems to be impaired, with subsequent postprandial EC overactivity, not only in obese individuals with reduced insulin sensitivity, but also in nonobese men with fatty liver and dyslipidemia, to an extent mostly independent from their BMI. If future studies will demonstrate that the dysregulated peripheral EC system is one of the underlying causes of insulin resistance, hepatic steatosis, and dyslipidemia, rather than their consequence, the present findings might improve our understanding of the aetiopathology of these metabolic disorders and, hence, open new avenues in their pharmacological treatment (29-31).

\section{Declaration of interest}

V Di Marzo was the recipient of a research grant from SanofiAventis. M-R Taskinen, who was the recipient of a research grant from Sanofi-Aventis, was on an advisory council for MSD, Astra-Zeneca and Novartis, received honoraria from MSD, Sanofi Aventis and Novartis, and has acted as a speaker in the speaker's bureau for Sanofi-Aventis. None of the other authors has any conflict of interests to disclose.

\section{Funding}

V Di Marzo was the recipient of a research grant from Sanofi-Aventis. The work at Helsinki University Hospital was supported by Sigrid Juselius Foundation, Clinical Research Institute HUCD Ltd Helsinki, Finland and HEPADIP (EU project code: ESHM-CT-2005-018734).

\section{Acknowledgements}

I Matias is now at U862, Centre de Recherche INSERM François Magendie, Bordeaux, France.

\section{References}

1 Di Marzo V. The endocannabinoid system in obesity and type 2 diabetes. Diabetologia 200851 356-1367.

2 Kunos G, Osei-Hyiaman D, Liu J, Godlewski G \& Bátkai S. Endocannabinoids and the control of energy homeostasis. Journal of Biological Chemistry 2008283 33021-33025.

3 Bensaid M, Gary-Bobo M, Esclangon A, Maffrand JP, Le Fur G, Oury-Donat $\mathrm{F} \&$ Soubrié $\mathrm{P}$. The cannabinoid $\mathrm{CB}_{1}$ receptor antagonist SR141716 increases Acrp30 mRNA expression in adipose tissue of obese fa/fa rats and in cultured adipocyte cells. Molecular Pharmacology 200363 908-914.

4 Osei-Hyiaman D, DePetrillo M, Pacher P, Liu J, Radaeva S, Bátkai S, Harvey-White J, Mackie K, Offertáler L, Wang L \& Kunos G. Endocannabinoid activation at hepatic $\mathrm{CB}_{1}$ receptors stimulates fatty acid synthesis and contributes to diet-induced obesity. Journal of Clinical Investigation 2005115 1298-1305.

5 Gary-Bobo M, Elachouri G, Gallas JF, Janiak P, Marini P, RavinetTrillou C, Chabbert M, Cruccioli N, Pfersdorff C, Roque C, Arnone M, Croci T, Soubrié P, Oury-Donat F, Maffrand JP, Scatton B, Lacheretz F, Le Fur G, Herbert JM \& Bensaid M. Rimonabant reduces obesity-associated hepatic steatosis and features of metabolic syndrome in obese Zucker fa/fa rats. Hepatology $2007 \mathbf{4 6} 122-129$.

6 Ruby MA, Nomura DK, Hudak CS, Mangravite LM, Chiu S, Casida JE \& Krauss RM. Overactive endocannabinoid signaling impairs apolipoprotein E-mediated clearance of triglyceride-rich lipoproteins. PNAS $2008 \mathbf{1 0 5} 14561-14566$.

7 Van Gaal LF, Scheen AJ, Rissanen AM, Rössner S, Hanotin C, Ziegler $\mathrm{O}$ \& RIO-Europe Study Group. Long-term effect of $\mathrm{CB}_{1}$ blockade with rimonabant on cardiometabolic risk factors: two year results from the RIO-Europe Study. European Heart Journal 200829 1761-1771.

8 Addy C, Wright H, Van Laere K, Gantz I, Erondu N, Musser BJ, Lu K, Yuan J, Sanabria-Bohórquez SM, Stoch A, Stevens C, Fong TM, De Lepeleire I, Cilissen C, Cote J, Rosko K, Gendrano IN III, Nguyen AM, Gumbiner B, Rothenberg P, de Hoon J, Bormans G, Depré M, Eng WS, Ravussin E, Klein S, Blundell J, Herman GA, Burns HD, Hargreaves RJ, Wagner J, Gottesdiener K, Amatruda JM \& Heymsfield SB. The acyclic CB1R inverse agonist taranabant mediates weight loss by increasing energy expenditure and decreasing caloric intake. Cell Metabolism 20087 68-78.

9 Blüher M, Engeli S, Klöting N, Berndt J, Fasshauer M, Bátkai S, Pacher P, Schön MR, Jordan J \& Stumvoll M. Dysregulation of the peripheral and adipose tissue endocannabinoid system in human abdominal obesity. Diabetes $2006553053-3060$.

10 Côté M, Matias I, Lemieux I, Petrosino S, Alméras N, Després JP \& Di Marzo V. Circulating endocannabinoid levels, abdominal adiposity and related cardiometabolic risk factors in obese men. International Journal of Obesity 200731 692-699.

11 Di Marzo V, Côté M, Matias I, Lemieux I, Arsenault BJ, Cartier A, Piscitelli F, Petrosino S, Alméras N \& Després JP. Changes in plasma endocannabinoid levels in viscerally obese men following a 1 year lifestyle modification programme and waist circumference reduction: associations with changes in metabolic risk factors. Diabetologia 200952 213-217. 
12 Matias I, Gonthier MP, Orlando P, Martiadis V, De Petrocellis L, Cervino C, Petrosino S, Hoareau L, Festy F, Pasquali R, Roche R, Maj M, Pagotto U, Monteleone P \& Di Marzo V. Regulation, function, and dysregulation of endocannabinoids in models of adipose and beta-pancreatic cells and in obesity and hyperglycemia. Journal of Clinical Endocrinology and Metabolism 200691 3171-3180.

13 Matias I, Petrosino S, Racioppi A, Capasso R, Izzo AA \& Di Marzo V. Dysregulation of peripheral endocannabinoid levels in hyperglycemia and obesity: effect of high fat diets. Molecular and Cellular Endocrinology 2008286 S66-S78.

14 Starowicz KM, Cristino L, Matias I, Capasso R, Racioppi A, Izzo AA \& Di Marzo V. Endocannabinoid dysregulation in the pancreas and adipose tissue of mice fed with a high-fat diet. Obesity 200816 553-565.

15 Izzo AA, Piscitelli F, Capasso R, Aviello G, Romano B, Borrelli F, Petrosino S \& Di Marzo V. Peripheral endocannabinoid dysregulation in two experimental models of obesity: potential relationships with intestinal motility and food deprivation/refeeding-induced energy processing. British Journal of Pharmacology 2009158 451-461.

16 Murdolo G, Kempf K, Hammarstedt A, Herder C, Smith U \& Jansson PA. Insulin differentially modulates the peripheral endocannabinoid system in human subcutaneous abdominal adipose tissue from lean and obese individuals. Journal of Endocrinological Investigation $200730 \mathrm{RC} 17-\mathrm{RC} 21$.

17 D'Eon TM, Pierce KA, Roix JJ, Tyler A, Chen H \& Teixeira SR. The role of adipocyte insulin resistance in the pathogenesis of obesity-related elevations in endocannabinoids. Diabetes $2008 \mathbf{5 7}$ $1262-1268$.

18 Monteleone P, Matias I, Martiadis V, De Petrocellis L, Maj M \& Di Marzo V. Blood levels of the endocannabinoid anandamide are increased in anorexia nervosa and in binge-eating disorder, but not in bulimia nervosa. Neuropsychopharmacology 200530 1216-1221.

19 Engeli S, Böhnke J, Feldpausch M, Gorzelniak K, Janke J, Bátkai S, Pacher P, Harvey-White J, Luft FC, Sharma AM \& Jordan J. Activation of the peripheral endocannabinoid system in human obesity. Diabetes $2005 \mathbf{5 4} 2838-2843$.

20 Lukaski HC, Johnson PE, Bolonchuk WW \& Lykken GI. Assessment of fat-free mass using bioelectrical impedance measurements of the human body. American Journal of Clinical Nutrition 198541 810-817.
21 Deurenberg P, Weststrate JA \& Hautvast JGAJ. Changes in fat-free mass during weight loss measured by bioelectrical impedance and by densitometry. American Journal of Clinical Nutrition 198949 33-36.

22 van der Kooy K \& Seidell JC. Techniques for the measurement of visceral fat: a practical guide. International Journal of Obesity and Related Metabolic Disorders 199317 187-196.

23 Tai MM. A mathematical model for the determination of total area under glucose tolerance and other metabolic curves. Diabetes Care 199417 152-154.

24 Adiels M, Taskinen MR, Packard C, Caslake MJ, Soro-Paavonen A, Westerbacka J, Vehkavaara S, Häkkinen A, Olofsson SO, YkiJärvinen H \& Borén J. Overproduction of large VLDL particles is driven by increased liver fat content in man. Diabetologia 200649 $755-765$.

25 Adiels M, Packard C, Caslake MJ, Stewart P, Soro A, Westerbacka J, Wennberg B, Olofsson SO, Taskinen MR \& Borén J. A new combined multicompartmental model for apolipoprotein B-100 and triglyceride metabolism in VLDL subfractions. Journal of Lipid Research 200546 58-67.

26 DeFronzo RA, Tobin JD \& Andres R. Glucose clamp technique: a method for quantifying insulin secretion and resistance. American Journal of Physiology 1979237 E214-E223.

27 Vogeser M \& Schelling G. Pitfalls in measuring the endocannabinoid 2-arachidonoyl glycerol in biological samples. Clinical Chemistry and Laboratory Medicine 200745 1023-1025.

28 Di Marzo V \& Petrosino S. Endocannabinoids and the regulation of their levels in health and disease. Current Opinion in Lipidology 200718 129-140.

29 Després JP. Pleiotropic effects of rimonabant: clinical implications. Current Pharmaceutical Design 200915 553-570.

30 Després JP, Ross R, Boka G, Alméras N, Lemieux I \& ADAGIOLipids investigators. Effect of rimonabant on the high-triglyceride/ low-HDL-cholesterol dyslipidemia, intraabdominal adiposity, and liver fat: the ADAGIO-Lipids trial. Arteriosclerosis, Thrombosis, and Vascular Biology 200929 416-423.

31 Scheen $\mathrm{AJ} \&$ Paquot $\mathrm{N}$. Use of cannabinoid $\mathrm{CB}_{1}$ receptor antagonists for the treatment of metabolic disorders. Best Practice and Research. Clinical Endocrinology and Metabolism 200923 103-116.

Received 27 August 2009

Accepted 4 September 2009 